05,12

\title{
Ориентационная зависимость магнитного момента микропроводов $\alpha$-Fe(PrDy)(CoFeB)
}

\author{
() О.В. Коплак ${ }^{1}$, Е.В. Дворецкая ${ }^{1}$, А.Д. Таланцев ${ }^{1}$, Д.В. Королев ${ }^{2}$, Р.А. Валеев ${ }^{2}$, \\ В.П. Пискорский ${ }^{2}$, А.С. Денисова ${ }^{3}$, Р.Б. Моргунов ${ }^{1,2,3}$ \\ ${ }^{1}$ Институт проблем химической фризики, \\ Черноголовка, Россия \\ ${ }^{2}$ Всероссийский институт авиационных материалов, \\ Москва, Россия \\ ${ }^{3}$ Первый московский государственный медицинский университет им. И.М. Сеченова, \\ Москва, Россия \\ E-mail: o.koplak@gmail.com
}

Поступила в Редакцию 12 декабря 2019 г.

В окончательной редакции 12 декабря 2019 г.

Принята к публикации 12 декабря 2019 г.

Исследована анизотропия намагниченности микропроводов, состоящих из ядра $\alpha$-Fe и оболочки $(\mathrm{PrDy})(\mathrm{FeCo}) \mathrm{B}$ при $300 \mathrm{~K}$. Разделены компоненты намагниченности ядра $\alpha$-Fe вдоль оси микропровода и неколлинеарная компонента оболочки микропровода с разными полями насыщения намагниченности $\sim 100$ Ое и $>10 \mathrm{kOe}$ соответственно. Направления намагниченностей оболочки и ядра отличаются на $170^{\circ}$.

Ключевые слова: ферромагнитные микропровода, магнитная анизотропия, размагничивающий фактор.

DOI: 10.21883/FTT.2020.04.49121.649

\section{1. Введение}

Магнитные микропровода привлекают внимание специалистов в связи с обширными применениями в качестве сенсоров магнитного поля, температуры, деформации, магнитных пинцетов и манипуляторов для биологии и медицины $[1,2]$. Одним из наиболее привлекательных свойств микропроводов является гигантский магнитоимпедансный эффект (GMI), вызванный влиянием магнитного поля на глубину скин-слоя $[3,4]$. Наблюдение GMI на уровне 1000\% и выше [5] свидетельствует о том, что область применения микропроводов может оказаться даже шире, чем для сложных в изготовлении гетероструктур планарной спинтроники, гигантское магнитосопротивление (GMR) которых обычно составляет сотни процентов [6]. Весьма перспективным представляется новый тип микропроводов с ядром $\alpha$-Fe и оболочкой $(\mathrm{PrDy})(\mathrm{FeCo}) \mathrm{B}$, о которых сообщалось в [7-10]. Эти микропровода, выращенные методом экстракции висящей капли расплава, диаметром $\sim 80-100 \mu \mathrm{m}$ и длиной 10-20 mm демонстрируют прямоугольную петлю гистерезиса из-за быстрого перемагничивания в ядре $\alpha$-Fe, низкое поле переключения намагниченности (менее 100 Ое) и высокую положительную магнитострикцию оболочки (PrDy) (FeCo)B. Контакт ферромагнитного ядра $\alpha$-Fe с ферримагнитной оболочкой (PrDy)(FeCo)B в этих микропроводах может создавать эффекты обменного смещения, что выглядит многообещающим с точки зрения комбинирования магнито-импедансных и магниторезистивных свойств. В литературе редко встречаются данные о микропроводах, содержащих переход- ные и редкоземельные элементы. Хотя возможность модификации магнитной фазы, и соответственно остаточной намагниченности, коэрцитивной силы и тд, в микропроводах на основе $\mathrm{NdFeB/Ta}$ были показаны в [11]. Коаксиальная двухфазная структура микропровода приводит не только к появлению эффекта GMI, но и к конкуренции магнитной анизотропии ядра и оболочки, которая приводит к формированию спирального [12] или азимутального [13] направления намагниченности в микропроводе. Данные о магнитной анизотропии ядра и оболочки микропровода могут быть получены из анализа анизотропии магнитных свойств микропровода. Цель настоящей работы заключалась в анализе магнитной анизотропии микропроводов, состоящих из ядра $\alpha$-Fe и оболочки $(\mathrm{PrDy})(\mathrm{FeCo}) \mathrm{B}$, полученных сверхбыстрым охлаждением расплава $(\mathrm{DyPr})(\mathrm{FeCo}) \mathrm{B}$.

\section{2. Методика и образцы}

Микропровода выращивались методом экстракции висящей капли расплава. Предварительно, многокомпонентный расплав нагревали в индукционной вакуумной печи. Ферробор и кобальт плавили в керамическом тигле, а затем добавляли $\operatorname{Pr}$ и Dу в расплав. Полученный расплав $\mathrm{PrDyFeCoB}$ охлаждали и слиток измельчали до среднего размера частиц $\sim 30 \mu \mathrm{m}$. Порошок $\mathrm{PrDyFeCoB}$ прессовали в форме призмы и спекали при $1140^{\circ} \mathrm{C}$ в вакууме $10^{-5}$ Torr. Спеченная призма подвергалась локальному облучению электронным пучком для локального плавления и образования капель расплава. Расплавленная капля соприкасалась с латунным цилиндром с водя- 
ным охлаждением, вращающимся с постоянной линейной скоростью поверхности $30-40 \mathrm{~m} / \mathrm{s}$, обеспечивающей скорость охлаждения $\sim 10^{6} \mathrm{~K} / \mathrm{s}$. Структурно-химический анализ извлеченных микропроводов был подробно описан ранее, включая идентификацию химического состава ядра $\alpha$-Fe и оболочки $\mathrm{PrDyFeCoB}$ [7-10]. Относительные объемные доли ядра $\alpha$-Fe и оболочки $\mathrm{PrDyFeCoB}$ приблизительно равны. Изображение микропроводов были получены на оптическом микроскопе AxioImager.A1 (Zeiss) и сканирующем автоэмиссионном электронном микроскопе SUPRA 25 (Zeiss). Во всех экспериментах использовались микропровода длиной $\sim 15 \mathrm{~mm}$ и диаметром $\sim 60-70 \mu \mathrm{m}$. Зависимости $M-H$ при комнатной температуре и угловые зависимости намагниченности были измерены на вибромагнитометре 7407 Lakeshore в режиме качающегося поля. Диапазон поля составлял от $-10 \mathrm{kOe}$ до $+10 \mathrm{kOe}$. Постоянная времени составляла $0.3 \mathrm{~s}$, а время усреднения составляло $1 \mathrm{~s}$ на точку.

\section{3. Экспериментальные результаты и обсуждение}

Микропровода имели форму, близкую к цилиндрической, длиной 2-3 mm и диаметром 50-70 $\mu \mathrm{m}$ (рис. 1). Зависимости магнитного момента микропровода от магнитного поля $M(H)$ показаны на рис. 2, a, для двух ориентаций магнитного поля вдоль и перпендикулярно оси микропровода. Полевые зависимости производной $d M / d H$ приведены на рис. 2, b. Как видно из рис. 2, $a$, в ориентации поля вдоль оси микропровода наблюдается его резкое перемагничивание в магнитном поле $H_{S} \sim 200-300$ Ое, что хорошо согласуется с ранее развитыми представлениями о бистабильности и однодоменности ядра микропроводов [1-3]. При перпендикулярной ориентации магнитного поля насыщение магнитного момента достигается в значительно большем поле эффективной анизотропии $H_{\text {shell }} \sim 10 \mathrm{kOe}$. Можно предполагать, что $H_{S} \sim 200-300$ Ое характеризует перемагничивание ядра микропровода, в то время, как $H_{\text {shell }} \sim 10 \mathrm{kOе}$ имеет отношение к магнитным свойствам оболочки.

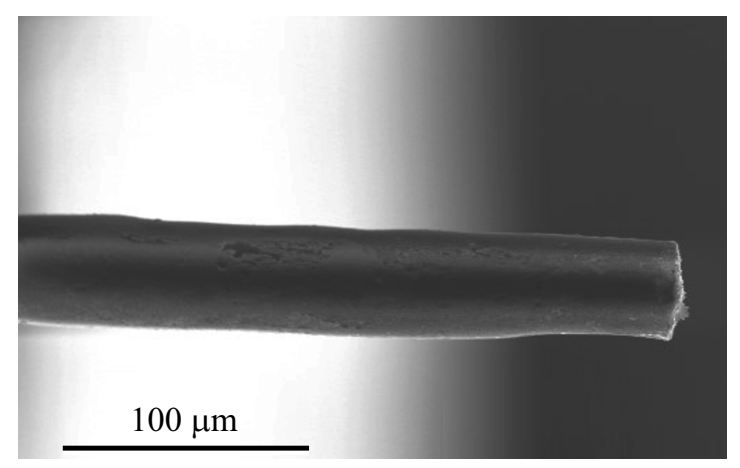

Рис. 1. Изображение цилиндрического микропровода $\alpha-\mathrm{Fe}(\mathrm{PrDy})(\mathrm{CoFe}) \mathrm{B}$.
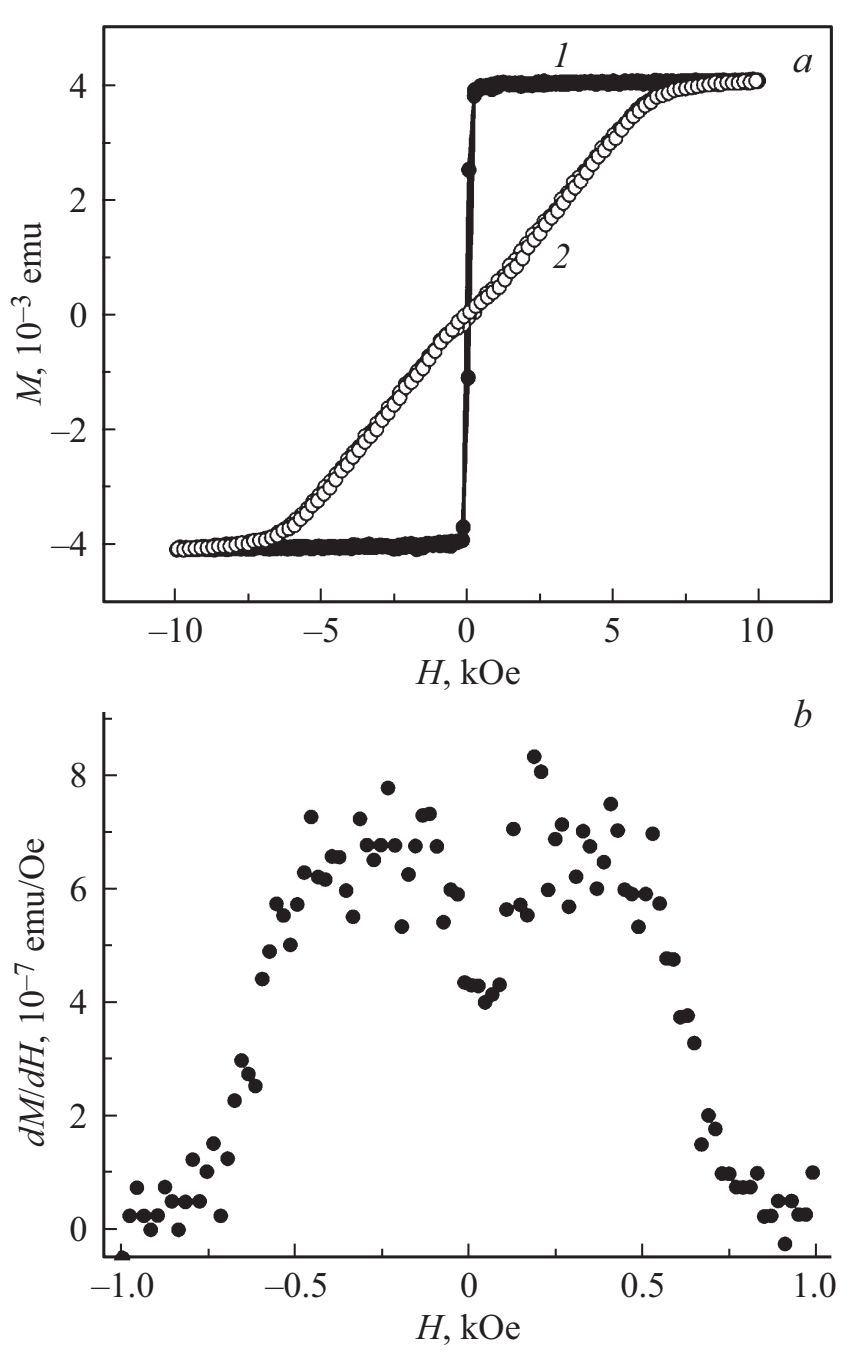

Рис. 2. (a) - Петли магнитного гистерезиса в магнитном поле, параллельном (1) и перпендикулярном (2) оси микропровода. На вставке показано сечение половины микропровода, полученной резким охлаждением в жидком азоте. $(b)$ - Зависимость магнитной восприимчивости $\chi=d M / d H$ от магнитного поля $H$ для ориентации поля перпендикулярно оси микропровода.

На вставке к рис. 3 показано сечение половины микропровода, приготовленной путем помещения цилиндрического образца в жидкий азот и расколотого пополам внутренними механическими напряжениями, возникшими при резком охлаждении. Из вставки на рис. 3 видно, что сечение микропровода соответствует правильному полуцилиндру, а аморфная оболочка неправильной формы имеет разную толщину вдоль оси микропровода вплоть до полного ее исчезновения.

Если не принимать во внимание наличие магнитного ядра и оболочки, из рис. 2, $a$ можно было бы сделать вывод, что главная ось намагниченности лежит вдоль оси микропровода, как это обычно бывает в результате анизотропии формы цилиндрического образца. Однако в слабых полях (рис. 2,a) имеется излом, который 

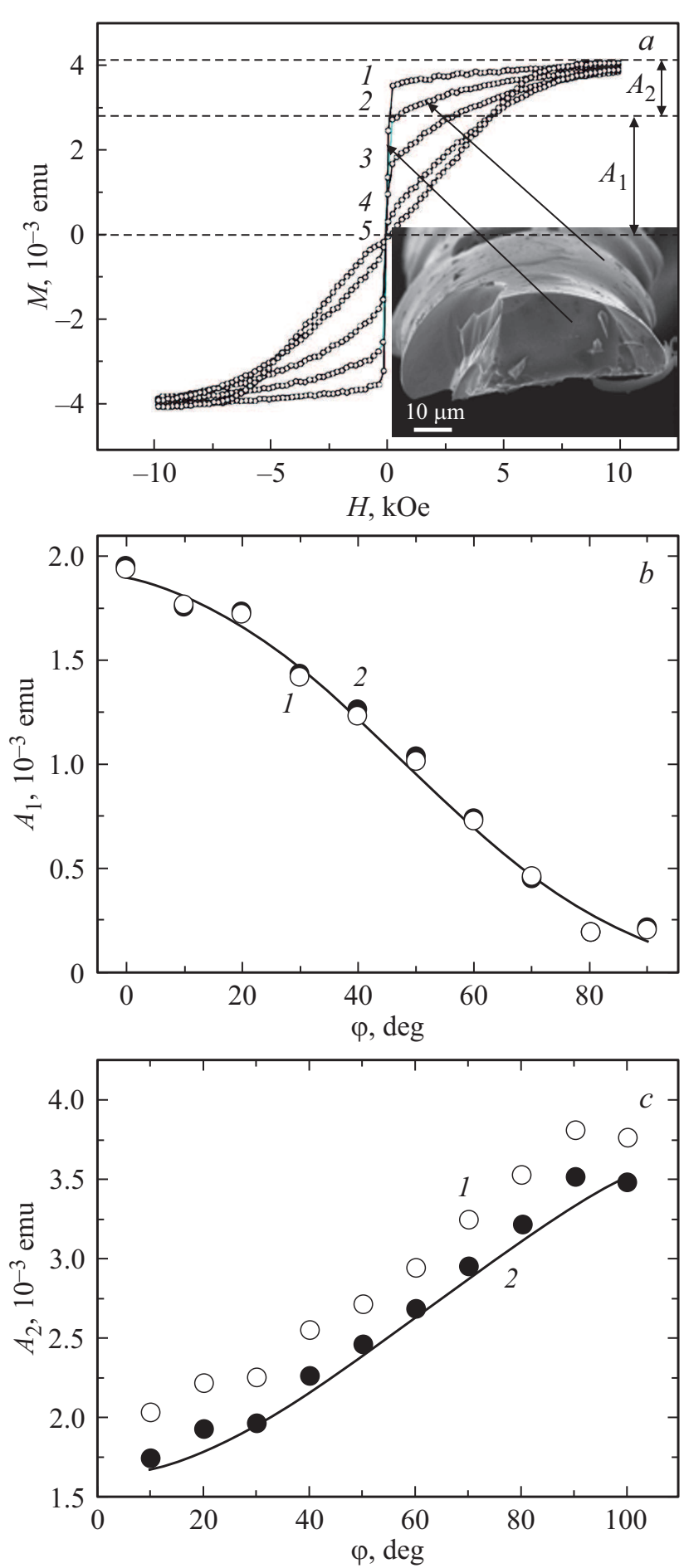

Рис. 3. (a) - Зависимости магнитного момента микропровода от магнитного поля, полученные при разных углах $\varphi$ между осью микропровода и магнитным полем: 1) $0^{\circ}$, 2) $\left.30^{\circ}, 3\right) 45^{\circ}$, 4) $60^{\circ}$, 5) $90^{\circ}$. Показаны параметры $A_{1}$ и $A_{2}$, отвечающие вкладам ядра и оболочки соответственно. Зависимости „низкополевой“ компоненты $A_{1}(b)$ и „высокополевой“ компоненты $A_{2}(c)$ от угла $\varphi$ в полях $1 \mathrm{kOe}(1)$ и $0.1 \mathrm{kOe}(2)$. Сплошными линиями показаны аппроксимации функциями $\cos \varphi$ и $\cos (\varphi+\pi / 2)$ соответственно. более явно виден как резкое изменение производной $d M / d H$ на ее зависимости от магнитного поля (рис. $2, b$ ). Видно, что при 0.3-0.4 kOе наблюдается максимум производной на зависимости $d M / d H(H)$, который обычно не наблюдается в однокомпонентных микропроводах или микропроводах покрытых немагнитным материалом (стеклом). Наличие такого максимума свидетельствует о том, что вклад ядра в полевую зависимость магнитного момента при перпендикулярной ориентации магнитного поля мал и перестает иметь значение при $H>300-400$ Oe.

Для проверки этого предположения полевые зависимости намагниченности были получены при нескольких разных углах вектора напряженности магнитного поля к оси микропровода $0^{\circ}, 30^{\circ}, 45^{\circ}, 60^{\circ}$ и $90^{\circ}$ (рис. $3, a$ ). Видно, что низкополевая часть зависимости $M(H)$ с амплитудой $A_{1}$ быстро насыщается в слабых полях (рис. $3, a)$ и уменьшается с ростом угла $\varphi$ в полях $0.1 \mathrm{kOe}$ и $1 \mathrm{kOe}$ (рис. 3,b). Остальная часть полевой зависимости $A_{2}$ насыщается в сильных полях $>10 \mathrm{kOe}$ (рис. $3, b)$ и растет с увеличением угла $\varphi$ между микропроводом и магнитным полем в полях $0.1 \mathrm{kOe}$ и $1 \mathrm{kOe}$ (рис. 3,c). Из этого можно сделать вывод, что намагниченность ядра микропровода $M_{\text {core }}$ направлена вдоль его оси и уменьшается, как $\cos \varphi$ с ростом угла. Проекция намагниченности оболочки $M_{\text {shell }}$, напротив, растет с увеличением угла $\varphi$.

Для независимого определения намагниченностей ядра и оболочки были получены ориентационные зависимости магнитного момента микропровода $M(\varphi)$ в магнитных полях 0 Ое (т.е. угловая зависимость остаточной намагниченности (рис. 4,a) и в магнитном поле $10 \mathrm{kOe}$, заведомо превышающем поле насыщения и ядра и оболочки (рис. 4,b). Видно, что ориентационная зависимость остаточной намагниченности в нулевом поле максимальна при направлении поля вдоль оси микропровода и в целом подчиняется функции $M=A_{1} \cos \varphi$, показанной сплошной линией. Остаточную намагниченность логично относить к ядру микропровода с продольной намагниченностью, в то время как аморфная редкоземельная оболочка, не имеющая гистерезиса в нулевом поле, дает нулевой вклад в ориентационные зависимости $M(\varphi)$. Небольшое отклонение от этой зависимости наблюдается при углах $\varphi=80-90^{\circ}$ (рис. 4, a). Это может быть связано с наличием ферромагнитных включений $\alpha$-железа в оболочке микропровода.

В почти насыщающем магнитном поле $10 \mathrm{kOe}$ (рис. 4,b), напротив, наблюдается минимум на зависимости $M(\varphi)$ при углах $\varphi=60-65^{\circ}$. Считая, что вклад оболочки остается прежним, (т.е. подчиняется функции $M=A_{1} \cos \varphi$ ), можно определить вклад оболочки, аппроксимируя экспериментальную зависимость магнитного момента суммой двух компонент оболочки и ядра: $M_{\text {core }}=A_{1} \cos \varphi$ и $M_{\text {shell }}=A_{2} \cos (\varphi+\theta)$, где $\theta$ - неизвестный угол ориентации намагниченности аморфной оболочки. На рис. $4, b$ сплошной линией 

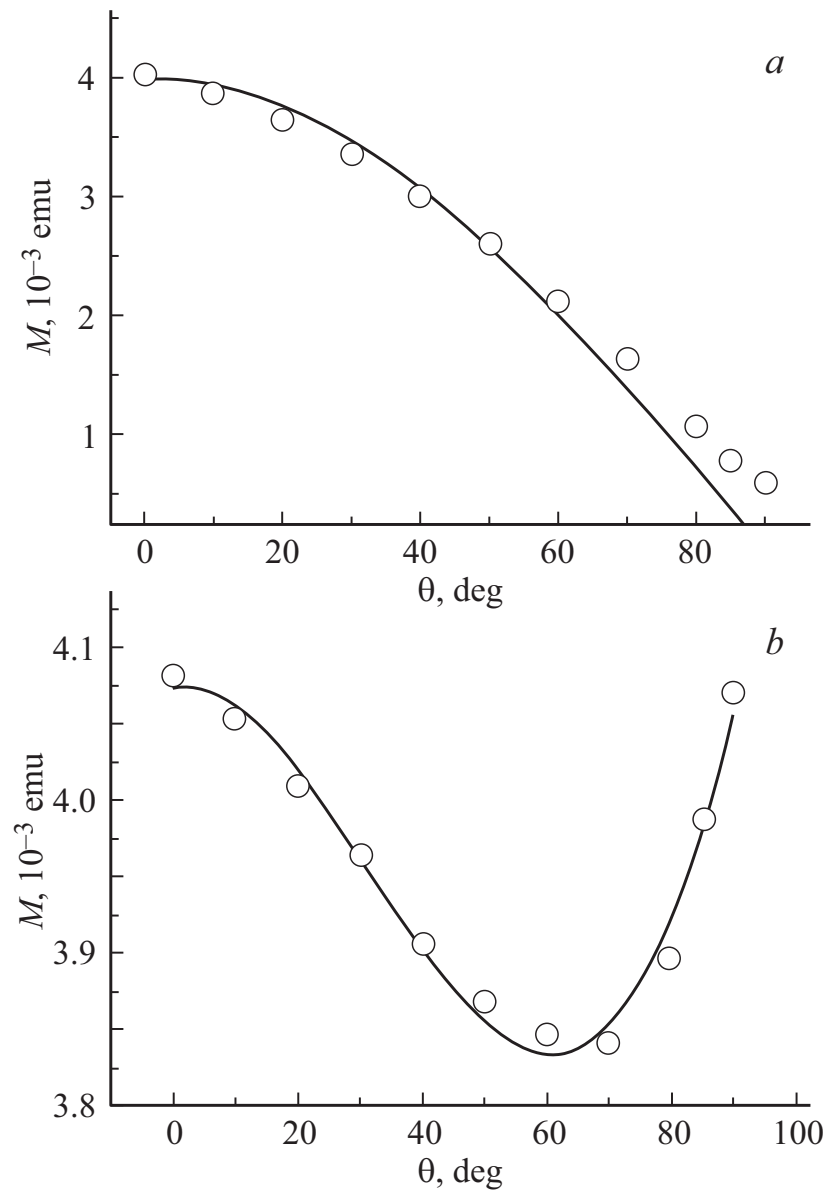

Рис. 4. Угловые зависимости магнитного момента микропровода, полученные в вибромагнетометре при постоянном значении магнитного поля: $(a) 0 \mathrm{kOe},(b) 10 \mathrm{kOe}$. Сплошными линиями показаны аппроксимации зависимостей, описанные в тексте.

показана аппроксимация экспериментальной ориентационной зависимости функцией $M(\varphi)=M_{\text {core }}+M_{\text {shell }}$ $=A_{1} \cos \varphi+A_{2} \cos (\varphi+\theta)$. Из этой аппроксимации определен угол $\theta=170^{\circ}$ наклона намагниченности оболочки по отношению к намагниченности ядра $\theta=0^{\circ}$. Из этого следует, что поле рассеяния ядра намагничивает аморфную оболочку почти в направлении силовых линий поля рассеяния, однако имеется небольшая перпендикулярная компонента. Аппроксимацией установлено, что в поле $10 \mathrm{kOe}$ амплитуда вклада ядра $A_{1}$ оказалась $\sim$ в 15 раз меньше амплитуды вклада оболочки $A_{2}$ (см. масштабы на рис. 4, $a, b)$, что вполне ожидаемо для редкоземельных ионов оболочки, которые дают большее поле насыщения. Это связано с тем, что суммарный момент элементарной единицы редкоземельной оболочки $S_{\text {DyPrFe }}=4$, т. е сумме спинового момента иона железа $S_{\mathrm{Fe}}=1 / 2$ (его орбитальный момент заморожен) и разности $J_{\mathrm{Dy}}-J_{\mathrm{Pr}}=15 / 2-4=7 / 2$ полных моментов ионов Dу и Pr. Поэтому ожидаемое отношение намагниченностей насыщения оболочки и ядра при их одинаковых объемах можно оценить по формуле: $A_{2} / A_{1}=S_{\text {DyPrFe }}\left(S_{\text {DyPrFe }}+1\right) / S_{\mathrm{Fe}}\left(S_{\mathrm{Fe}}+1\right)=13.3$. Различие экспериментально полученного значения $A_{2} / A_{1}=15$ и теоретической оценки $A_{2} / A_{1}=13.3$ может быть связано с неточным определением объемов ядра и оболочки, отношение которых не постоянно вдоль оси микропровода (см. вставку на рис. 2). Таким образом, аппроксимация угловой зависимости магнитного момента двумя угловыми зависимостями с разной фазой и периодом удовлетворительно предсказывает отношение намагниченностей насыщения оболочки и ядра микропровода.

Угловая зависимость коэрцитивной силы $H_{c}$ в магнитном поле $1 \mathrm{kOe}$ приведена на рис. 5. Она аппроксимирована зависимостью $H_{c}(\varphi)=H_{c 0} / \cos \varphi$ (сплошная линия), которая, согласно теоретическим представлениям о движении $180^{\circ}$ доменной стенки [14], характеризует процесс перемагничивания ядра микропровода. Пропорциональность коэрцитивной силы фактору $H_{c 0} / \cos \varphi$ отвечает ситуации, когда перемагничивание происходит путем нуклеации зародышей обратной намагниченности [15]. При этом параметр $H_{c 0}=20$ Ое в сложной композитной системе микропровода отвечает полю открепления доменных стенок от препятствий [15].

В заключение отметим, что наши простые оценки отнюдь не решают вопроса о сложном магнитном состоянии оболочки микропровода. Отдельных исследований и обсуждения требует наличие включений $\alpha$-железа в оболочке, установленное нами в предыдущих работах, магнитное дипольное взаимодействие между ядром и оболочкой, а также обменное смещение, обнаруженное ранее с помощью микроскопии Керра $[9,10]$. Все эти факторы способны формировать сложную угловую зависимость намагниченности оболочки, как было ранее показано в работах, посвященных многослойным микропроводам [16-20]. В этой работе установлена лишь неколлинеарность намагниченностей ядра и оболочки в сильных магнитных полях на уровне $10 \mathrm{kOe}$. Обсужде-

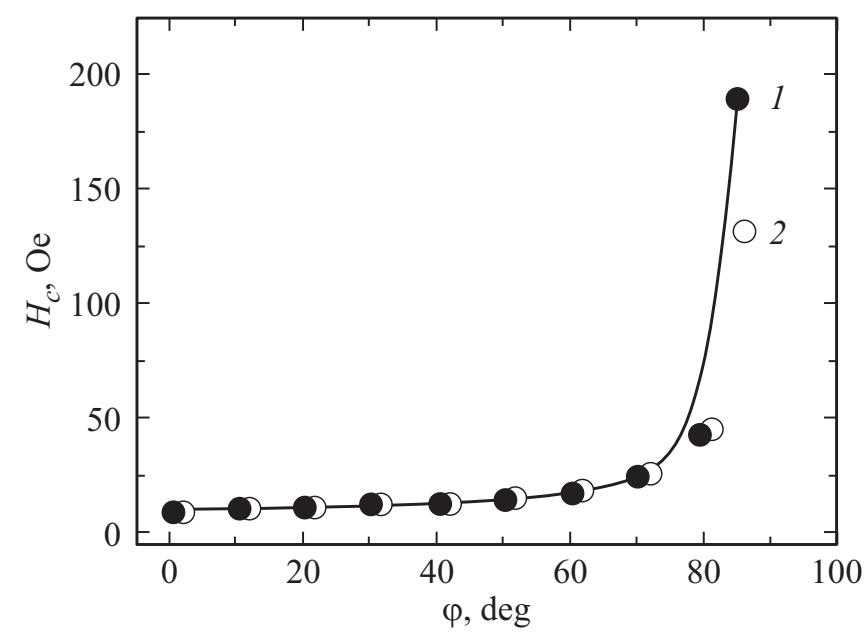

Рис. 5. Угловые зависимости коэрцитивной силы $H_{c}$ микропровода в магнитных полях $0.1 \mathrm{kOe}(1), 1 \mathrm{kOe}(2)$. Сплошной линией показана аппроксимация зависимости при $0.1 \mathrm{kOe}$. 
ние природы магнитной анизотропии оболочки, которая к тому же может оказаться частично кристаллизованной в виде наночастиц, требует детального анализа свойств и фазового состава сплава $\mathrm{PrDyFeCoB}$.

\section{4. Выводы}

1. Полевые зависимости магнитного момента микропровода $\alpha$-Fe в оболочке (PrDy)(FeCo)B состоят из двух компонент. Компонента магнитного момента $\alpha$-Fe ядра микропровода насыщается в слабых полях $\sim 100 \mathrm{Oе}$, уменьшается с ростом угла между полем и осью микропровода и направлена вдоль его оси. Компонента намагниченности редкоземельной оболочки (PrDy)(FeCo)B насыщается в поле $>10 \mathrm{kOe}$, нарастает при отклонении поля от оси микропровода и неколлинеарна оси микропровода.

2. Угловые зависимости магнитного момента микропровода $\alpha$-Fe в оболочке $(\mathrm{PrDy})(\mathrm{FeCo}) \mathrm{B}$ имеют минимум при направлении магнитного поля под углом 10-30 к оси микропровода в магнитном поле 5-10 kOe. Этот минимум проявляется только в сильных полях, близких к полю насыщения оболочки микропровода, что свидетельствует о наличии компоненты намагниченности оболочки, неколлинеарной оси микропровода.

3. Угловая зависимость коэрцитивной силы $\alpha$-Fe ядра микропровода в слабых полях следует закономерности Кондорского $H_{c} \sim 1 / \cos \varphi$, отвечающей механизму нуклеации, ограниченному $180^{\circ}$ доменной стенкой в ядре микропровода.

\section{Финансирование работы}

Работа выполнена при поддержке РФФИ проект 20-3270025 „Стабильность“. Р.Б. поддержан проектом по повышению конкурентоспособности ведущих российских вузов среди научно-образовательных центров (5-100).

\section{Конфликт интересов}

Авторы заявляют, что у них нет конфликта интересов.

\section{Список литературы}

[1] H.-X. Peng, F. Qin, M.-H. Phan. Ferromagnetic microwire composites: from sensors to microwave applications. Ser. Engineering Materials and Processes. Springer, (2016). 245 p.

[2] M. Vazquez, H. Chiriac, A. Zhukov, L. Panina, T. Uchiyama. Phys. Status Solidi, 208, 3, 493 (2011).

[3] V. Zhukova, M. Ipatov, J. Gonzalez, J.M. Blanco, A. Zhukov. J. Appl. Phys. 103, 7, 07E714 (2008).

[4] V. Zhukova, M. Ipatov, A. Zhukov. Sensors 9, 11, 9216 (2009).

[5] V.V. Popov, V.N. Berzhansky, H.V. Gomonay, F.X. Qin. J. Appl. Phys. 113, 17, 17A326 (2013).

[6] A. Fert. Rev. Mod. Phys., 80, 4, 1517 (2008).
[7] R.B. Morgunov, O.V. Koplak, V.P. Piskorskii, D.V. Korolev, R.A. Valeev, A.D. Talantsev. J. Magn. Magn. Mater. 497, 166004 (2020).

[8] В.П. Пискорский, Р.А. Валеев, Д.В. Королев, Р.Б. Моргунов, И.И. Резчикова. Тр. ВИАМ 7, 79, 59 (2019).

[9] Р.Б. Моргунов, О.В. Коплак, А.Д. Таланцев, Д.В. Королев, В.П. Пискорский, Р.А. Валеев. Тр. ВИАМ 7, 79, 67 (2019).

[10] О.В. Коплак, В.Л. Сидоров, Е.И. Куницына, Р.А. Валеев, Д.В. Королев, В.П. Пискорский, Р.Б. Моргунов. ФТТ 61, 11, 2090 (2019).

[11] R. Szary, I. Luciu, D. Duday, E.A. Perigo, T. Wirtz, P. Choquet, A. Michels. J. Appl. Phys., 117, 17D134 (2015).

[12] G. Kurlyandskaya, P. Jantaratana, M. Cerdeira, V. Va'kovskiy. World J. Condens. Matter Phys., 3, 1, 21, (2013).

[13] A. Chizhik, V. Zhukova. Phys. Res. Int., 690793 (2012).

[14] L. Janh, K. Elk, R. Schumann, J. Magn. Magn. Mater. 68, 335(1987).

[15] H. Kronmuller, K.D. Durst, G. Martinek. J. Magn. Magn. Mater. 69, 149(1987).

[16] J. Escrig, S. Allende, D. Altbir, M. Bahiana, J. Torrejon, G. Badini, M. Vazquez. J. Appl. Phys. 105, 2, 023907 (2009).

[17] V. Zhukova, M. Ipatov, J.J. del Val, A. Granovsky, A. Zhukov. IEEE Transact. Magn. 54, 6, 1 (2018).

[18] A. Zhukov, V. Rodionova, M. Ilyne, A.M. Aliev, R. Varga, S. Michalik, A. Aronin, G. Abrosimova, A. Kiselev, M. Ipatov, V. Zhukova, J. Alloys Comp., 575, 73 (2013).

[19] J. Torrejóna, L. Kraus, K.R. Pirota, G. Badini, M. Vázquez. J. Appl. Phys., 101, 09N105 (2007).

[20] J. Escrig, S. Allende, D. Altbir, M. Bahiana, J. Torrejón, G. Badini, M. Vázquez. J. Appl. Phys. 105, 023907 (2009).

Редактор К.В. Емцев 